\title{
In vitro and in vivo antidiabetic effect of Andrographis lineata Wall. Ex.Nees and Andrographis serphyllifolia Wt.Ic leaf extracts
}

\author{
V. Sudarshana Deepa ${ }^{1 \star}$, K. Rajaram ${ }^{2}$, P. Suresh Kumar ${ }^{2}$ \\ 1Department of Biotechnology, Bannari Amman Institute of Technology, Sathyamangalam-638401, Tamilnadu, India. \\ ${ }^{2}$ Department of Biotechnology, Anna University Chennai (BIT campus), Tiruchirappalli-620024, Tamilnadu, India.
}

Accepted 10 June, 2013

Andrographis lineata and Andrographis serphyllifolia are endemic potential medicinal plants of South India. The leaves of both the herbs have been used as ancient folklore medicine for curing diabetes, snakebite, inflammation and cancer. The present investigation deals with the study of in vitro and in vivo antidiabetic effect of the ethanolic leaf extract of $A$. lineata (EtALL) and ethanolic leaf extract of $A$. serphyllifolia (EtASL). Qualitative analysis of phytochemicals revealed the presence of alkaloids, tannins, terpenoids, steroids, flavanoids and polyphenol compounds, absence of saponins and steroids in both the extracts. The $\alpha$-glucosidase inhibition results of EtALL (IC ${ }_{50}$ value $10.12 \mu \mathrm{g} / \mathrm{ml}$ ) and EtASL (IC 50 value $11.39 \mu \mathrm{g} / \mathrm{ml}$ ) exhibited stronger inhibitory activity for $\alpha$-glucosidase which was comparable with Acarbose. The 3-[4, 5-dimethylthiazol-2-yl]-2, 5-diphenyltetrazolium bromide (MTT) assay of the EtALL and EtASL extracts in 3T3-L1cell line confirmed that there was no toxicity effect for both the extracts from 6.5 to $50 \mu \mathrm{g} / \mathrm{ml}$ concentrations. The glucose uptake rate in 3T3-L1 cells revealed the fact that both the extracts showed increase in glucose uptake rate in dose dependent manner comparable to insulin. Further these extracts were evaluated in the in vivo model to prove the traditional claim of usage pertaining to antidiabetic property. The acute toxicity studies showed that there was no death or lethal effect observed in toxicity study. The acute treatment of fasting blood sugar and oral glucose tolerance test of EtALL and EtASL extract $(400 \mathrm{mg} / \mathrm{kg}$ b.w.) treated normoglycemic rats showed hypoglycemic effect. When the streptozotocin induced diabetic rats was administered with EtALL and EtASL $400 \mathrm{mg} / \mathrm{kg} \mathrm{b.w.} \mathrm{in} \mathrm{chronic} \mathrm{model} \mathrm{(28} \mathrm{days)} \mathrm{there} \mathrm{was} \mathrm{a} \mathrm{significant} \mathrm{reduction} \mathrm{in} \mathrm{plasma} \mathrm{glucose,}$ plasma insulin level, total cholesterol, low density lipoprotein (LDL)-c triglyceride, glucose-6phosphatase and fructose -1, 6- bisphosphatase levels. Glycogen content (liver and muscle), high density lipoprotein (HDL) cholesterol, hexokinase, was significantly increased compared with the diabetic control rats in both the extracts treated rats. The above findings showed the significant antidiabetic potential of the extracts in ameliorating the diabetic condition in the diabetic treated rats. Further studies are in progress to identify the active principle's possible for the antidiabetic effect in EtALL and EtASL extracts.

Key words: Antidiabetic activity, 3T3-L1 cell lines, a-glucosidase inhibition, streptozotocin.

\section{INTRODUCTION}

Diabetes mellitus (DM) consists of a group of syndromes characterized by hyperglycemia, altered metabolism of lipids, carbohydrates, and proteins, and an increased risk of complications from vascular disease (Davis, 2006). Modern medicines such as biguanides, sulfonylureas and thiozolidinediones are available for the treatment of 
diabetes. However they have undesired side effects associated with their uses (Zimmet et al., 2001). Alternative medicines, predominantly herbal drugs are effective, safer and acceptable to the general society (Valiathan, 1998). One of the therapeutic approach for treating type 2 diabetes is (T2D) is to decrease postprandial hyperglycemia. The medicinal plants or natural products involve retarding the absorption of glucose by inhibiting the carbohydrate hydrolyzing enzymes- a-glucosidase, that is, Tephrosia tinctoria (Rajaram and Sureshkumar, 2011), Verbascum kermanesis, Rosa damascene, Rosmarinus officinalis, Levisticum officinale, Zataria multiflora, Sanguisoba minor, Alhagi camelorum, Pistacia vera, Vaccinium arcto staphylus (Ahmad et al., 2008). The inhibition of these enzymes delay carbohydrate digestion and protect carbohydrate overall digestion time, resulting in the reduction in glucose absorption rate and dulling of postprandial plasma glucose rise (Tadera et al., 2006).

T2D, which may also be caused by metabolic syndrome, is characterized by a reduced sensitivity to insulin signaling and a reduced efficiency of glucose transport, primarily in adipocytes and muscle cells, leading to hyperglycemia and hyperinsulinemia (Cho et al., 2004). Adipose tissue is considered as a key link between obesity and T2D by promoting the development of lipotoxicity, that is, cell damage as a consequence of elevated intracellular lipid concentrations and insulin resistance (Lelliott and Vidal-Puig, 2004). Pathways related to insulin resistance are studied in cell lines of adipocytes such as murine 3T3-L1 cells employed as tools to evaluate the effects of natural products upon glucose uptake (Karalee et al., 2001). Apart from the available in vitro models to study the various target sites of diabetes animal model evaluation for diabetes are greatly useful and advantages because they offer promise of new sights into human diabetes. Inbred animal models, in which the genetic background is homogemous and environmental factors which can be controlled, are therefore valuable in genetic dissection of multifactorial diseases. Streptozotocin is one such frequently used animal model for T2D (Patil et al., 2011).

Andrographis lineata Wall.ex.Nees (AL) and Andrographis serpyllifolia Wt.lc (AS) are members of Acanthaeceae family. The former is an erect perennial herb and latter is a trailing and rooting herb, both are widely distributed throughout Deccan and Carnatic regions of South India (Gamble, 1956). All the parts of AL and AS are important in the traditional system of medicine in India which has been extensively used for snake bites, diabetes, antipyretics, cancer and inflammation (Ignacimuthu et al., 2006; Damu et al., 1999). There are reports on antimicrobial, diuretic and hepatoprotective activity of AL leaf extracts (Alagesaboopathi and balu, 1995; Ignacimuthu et al., 2006; Sangameswaran et al., 2007). Flavanoids were isolated from the whole plant extract of AL (Kishore et al., 2003). The phytochemicals reported for AS are serpyllin, apigenin, 7, 4, 1-dimethyl ether, techtochrysin, andrographine from the whole plant extract of AS (Sathish et al., 2009). Anticancer and hypolipidemic activity has been evaluated in the leaf and root extracts of AS (Bharath and Manga, 2010; Govindachari et al., 1968). Though the leaves of both the plants have been used as ancient folklore medicine for diabetes by the tribals of Kolli Hills of Nammakal District, Tamilnadu, India, till now there is lack of scientific documentation.

The prolonged hyperglycemia that results in diabetic patients has been speculated to induce oxidative stress through the excessive generation of free radicals which may impair endogenous antioxidant defense (Srinivasan and Ramarao, 2007). The stabilization of blood glucose in diabetic patients is therefore important to prevent these hyperglycemic complications. The main therapeutic approach used to achieve this objective in the diabetic patient is to stimulate insulin release, increase the number of glucose transporters, inhibit gluconeogenesis or reduce the absorption of glucose. Another therapeutic approach is to decrease the post-prandial hyperglycemia, which is achieved with the enzyme inhibitors such as acarbose, voglibose and miglitol (Chiasson et al., 1994) which function by retarding the action of the gastrointestinal carbohydrate hydrolysing enzymes $\alpha$-amylase and $\alpha$-glucosidase. As a result, these substances delay carbohydrate digestion thereby decreasing the rate of glucose absorption, that is, they blunt the post-prandial plasma glucose rise. While effective, the gastrointestinal side effects of acarbose, which includes bloating, abdominal discomfort, diarrhoea, and flatulence, make them less attractive as therapeutic agents. Glucose uptake and storage in peripheral tissues such as skeletal muscles and adipose tissue is a major regulatory process in the homeostatic control of blood glucose levels (Satish et al., 2011).

It is widely accepted that skeletal muscle, by virtue of its large contribution to body mass, represents the major site of insulin-mediated glucose disposal. However, both tissues contribute toward the lowering of blood glucose (Ji-Youn et al., 2004). Glucose uptake is mediated through the translocation of the Glut4 receptor from the interior to the cell surface which is stimulated by the insulin signaling pathway initiated by activation of the insulin receptor. Any defect in this pathway triggers the development of hyperglycemia in type II diabetes. Thus, measurement of glucose uptake into peripheral tissues is an important mechanism to assess insulin sensitivity. Insulin sensitizers like thiazolidinediones (TZDs) are effective in improving insulin resistance; however their adverse effect profile limits their long term use (Karalee et al., 2001).

New anti-diabetic compounds which function by this mechanism but devoid of side effect are therefore desirable. Hence an attempt was made to evaluate the antidiabetic activity of ethanolic leaf extracts of $A$. lineata Wall.ex.Nees (EtALL) and A. serpyllifolia Wt.lc (EtASL) in vitro (a-glucosidase inhibition and glucose uptake activity) 
and in vivo (Streptozotocin induced Wistar male rats) study.

\section{MATERIALS AND METHODS}

\section{Plant material}

$\mathrm{AL}$ and AS were collected from Kolli Hills of Nammakal District of Tamil Nadu,India and the plant material was identified by BSI (Botanical Survey of India, Coimbatore, Tamil Nadu, India). The voucher specimen AL and AS ( BSI/SC/5/23/07-08/Tech.1803) was deposited in Rappinart Herbarium, St .Joseph's College, Tiruchirappalli, Tamilnadu, India. The leaves of AL and AS were shade dried at room temperature, finely powdered. The EtALL and EtASL was prepared using Soxhlet apparatus at $60^{\circ} \mathrm{C}$ and concentrated using rotary evaporator at $40^{\circ} \mathrm{C}$ stored in a desiccators till further use.

\section{Phytochemical screening}

Preliminary qualitative analysis of EtALL and EtASL extracts were performed by employing standard procedures (Trease, 2005) to reveal the presence of chemical constituents such as alkaloids, flavanoids, tannins, terpenes, saponins, glycosides and steroids.

\section{In vitro a-glucosidase inhibitory assay}

In order to investigate the inhibitory effect of EtALL and EtASL extracts, an in vitro $\alpha$-glucosidase inhibition assay was performed based on the methodology of Sunil et al. (2009). The a-glucosidase inhibitory effect was calculated using the formula:

$\%$ Inhibition = (Absorbance of Control $)-($ Absorbance of test sample) /Absorbance of control X100

Acarbose (Sigma,U.S.A) a well known a-glucosidase inhibitor was used as reference drug for the inhibitory activity. The a-glucosidase inhibitory activities of EtALL and EtASL extracts and Acarbose was calculated and the $\mathrm{IC}_{50}$ value was determined.

\section{T3-L1 cell culture maintanance and adipocyte differentiation}

Adipocyte differentiation was induced and glucose uptake activity was assessed according to the method of Liu et al. (2001). 3T3-L1 cells (NCCS, Pune, India) were grown in Dulbecco's modified Eagle's medium (DMEM) medium (Himedia, Mumbai, India) and supplemented with $10 \%$ fetal bovine serum (FBS) (Himedia, Mumbai, India) at $37^{\circ} \mathrm{C}$ to attain confluency in 12-well plates. Adipocyte differentiation was induced by supplementing the media with a combination of $166.7 \mathrm{nmol} / \mathrm{I}$ insulin (Sigma, USA) , 540.5 $\mu \mathrm{mol} / \mathrm{I} \mathrm{IBMX}$ (Sigma,USA), and $255.1 \mathrm{nmol} / /$ DEX (Sigma,USA) for $48 \mathrm{~h}$ followed by insulin alone and EtALL and EtASL extracts of different concentration for an additional $48 \mathrm{~h}$. The media was then replaced with fresh culture medium (DMEM supplemented with $10 \%$ FBS) after 2 days and then every three day thereafter. Cell viability and glucose uptake experiments were performed 11-12 days post induction of differentiation.

\section{Cell viability}

Preconfluent 3T3-L1 preadipocytes were seeded in 96-well plates at a density of 10,000 cells/well. Untreated cells and cells treated with EtALL and EtASL extracts with concentration (6.5, 12.5, 25, 50, 100 and $200 \mu \mathrm{g} / \mathrm{ml}$ ) and with positive control (Cyclophosphamide) at $45 \mu \mathrm{g} / \mathrm{ml}$ were subsequently added to culture medium at the time of plating. At $48 \mathrm{~h}$ following plating, the cells were incubated at $37^{\circ} \mathrm{C}$ with $0.5 \mathrm{mg} / \mathrm{ml} \mathrm{MTT}$ for $45 \mathrm{~min}$. The medium was aspirated, and the insoluble formazan product was dissolved in DMSO (250 $\mu \mathrm{l})$ for at least $2 \mathrm{~h}$ in the dark. MTT reduction was quantified by measuring the absorbance at $550 \mathrm{~nm}$.

\section{Glucose uptake activity assay}

Glucose uptake activity was analyzed by measuring the uptake of 2-deoxy-D-[3H] glucose (Yu et al., 2003). Confluent 3T3-L1 adipocytes grown in 12-well plates were washed twice with serumfree DMEM and incubated with $0.5 \mathrm{ml}$ of the same medium at $37^{\circ} \mathrm{C}$ for $2 \mathrm{~h}$. The cells were washed three times with KRP buffer and incubated with $0.9 \mathrm{ml} \mathrm{KRP}$ buffer at $37^{\circ} \mathrm{C}$ for $30 \mathrm{~min}$. EtALL and EtASL extracts of concentrations $(50,100,200$ and $500 \mu \mathrm{g} / \mathrm{ml})$ were then added and adipocytes were further incubated at $37^{\circ} \mathrm{C}$ for 20 min. Glucose uptake was initiated by the addition of $0.1 \mathrm{ml} \mathrm{KRP}$ buffer containing $0.037 \mathrm{MBq} / \mathrm{l} 2$-deoxy-D-[3H] glucose and 0.001 $\mathrm{mmol} / \mathrm{I}$ glucose. After $15 \mathrm{~min}$, the assay was terminated by washing the cells three times with cold PBS. The cells were lysed with $0.7 \mathrm{ml}$ of $1 \%$ Triton $\mathrm{X}-100$ at $37^{\circ} \mathrm{C}$ for $20 \mathrm{~min}$. The radio activity retained by the cell lysates was determined by a scintillation counter (Tri-Carb 2100TR, Packard, USA). The effect of EtALL and EtASL extracts on glucose uptake increase rate in 3T3-L1 adipocytes was calculated as follows:

Glucose uptake increase rate $(\%)=\left(A s / A_{0}\right) \times 100$.

Here, $A_{S}$ is the glucose uptake of EtALL and EtASL extracts of different concentrations and $A O$ is the glucose uptake of blank (without EtALL or EtASL extract).

\section{Animals}

Male Wistar rats weighing $170 \pm 5 \mathrm{~g}$ were procured from Tamilnadu Vetinary Science University, Chennai and acclimatized at the temperature of $23 \pm 2^{\circ} \mathrm{C}$ with controlled humidity conditions (50-55 $\%)$ at $12 \mathrm{~h}$ light and dark cycle. The rats were kept in polypropylene cages and were fed with standard pellet diet (Sri Venkateswara Enterprises, Bangalore, India) and water ad libitum. All the studies conducted were approved by the Institutional Animal Ethical Committee of PRIST University (East Campus), (Reg.No.743/abc/CPCSEA, PhD2/2011-12), Thanjavur-614904, Tamilnadu, India according to the prescribed guidelines of CPCSEA, Government of India.

\section{Acute toxicity study}

Healthy adult male Wistar rats were starved overnight, divided into five groups $(n=6)$ and were orally fed with EtALL and EtASL extracts at increasing dosage level $(100,500,1000,2000$ and 4000 $\mathrm{mg} / \mathrm{kg}$ b.w.) respectively (Gosh, 1984). The animals were observed continuously for $2 \mathrm{~h}$ under behavioural, neurological and autonomic profiles. After a period of 24 to $72 \mathrm{~h}$ of incubation they were observed for lethality or death (Turner, 1965).

\section{Effect of EtALL and EtASL extract in normoglycemic rats}

The fasting blood sugar level of each animal was determined after overnight fasting for 16 h.Normoglycemic rats were divided into 5 groups ( $n=6$ per group). Saline was administered orally to the 
control group (Group 1), 200 and 400 mg/kg b.w. EtALL (Group 2 and Group 3) and EtASL extract (Group 4 and Group 5) was administered, respectively. Blood samples were collected at 30,60 , 90 and 120 min after administration of the extracts (Triender, 1969).

\section{Oral glucose tolerance test (OGTT) in normoglycemic rats}

The oral glucose tolerance test was performed on overnight fasted (18 h) normal rats (Bonner-Weir, 1988). Rats were divided into ten groups $(n=6)$, Saline was administered to Group 1; 200 and 400 $\mathrm{mg} / \mathrm{kg}$ of EtALL and EtASL extract alone was given to Group 2, Group 3, Group 4 and Group 5. Diabetic control induced with streptozotocin (Group 6). Diabetic induced rat were treated with 200 and $400 \mathrm{mg} / \mathrm{kg}$ b.w EtALL (Group 7 and Group 8) and EtASL (Group 9 and Group 10) extract. Glucose (2 g/kg p.o.) was fed after $30 \mathrm{~min}$ to all the groups. Blood was withdrawn from the retro orbital sinus under ether inhalation at 30,60 and $120 \mathrm{~min}$ of glucose administration and glucose levels were estimated by using glucose oxidase -peroxidase reactive strips and a glucometer (Sugarcheck, Wockhardt, Mumbai, India).

\section{Induction of diabetes}

Diabetes was induced by single intraperitoneal injection of streptozotocin (STZ), (Sigma, USA) dissolved in freshly prepared $0.1 \mathrm{M}$ citrate buffer at $\mathrm{pH}$ 4.5. After seven days of STZ administration (40 mg/kg b.w.), blood glucose level was determined. Rats with blood glucose level above $200 \mathrm{mg} / \mathrm{dl}$ were considered diabetic and included in the study.

\section{Experimental design}

In the experiment, a total of 30 rats $(6$ normal and 24 STZ diabetic surviving rats) were used. These rats were divided into six groups of 6 rats each. The extract was dissolved in $2 \%$ tween 80 solutions and administered orally for 4 weeks. Group I, Normal control rats; Group II, diabetic control rats; Group III, diabetic rats treated with $400 \mathrm{mg} / \mathrm{kg}$ b.w. EtALL extract; Group IV, diabetic rats treated with $400 \mathrm{mg} / \mathrm{kg}$ b.w. EtASL extract; Group V, diabetic rats treated with $600 \mu \mathrm{g} / \mathrm{kg}$ b.w. glibenclamide.

At the end of the $28^{\text {th }}$ day of study, the animals were sacrificed. Blood was collected in tubes containing potassium oxalate and sodium fluoride solution (anticoagulant) which was used for estimation of blood glucose. The blood glucose levels for $0,14^{\text {th }}$ and $28^{\text {th }}$ day and OGTT were estimated using a GOD-POD method. Fasting glucose level was estimated by glucose oxidase-peroxidase method (Triender, 1969). The plasma insulin was assayed by enzyme linked immuno sorbent assay (ELISA) (Boehringer analyzer ES 300) using Boehringer-Mannheim kit following the manufacturer's instructions. The glycogen level of liver and skeletal muscles was measured by anthrone method (Carrol et al., 1956). The liver tissues from the experimental animals were dissected, washed in ice cold saline, patted dry and weighed. $100 \mathrm{mg}$ tissue was cut and homogenized in appropriate buffer using teflon pestle. The tissue homogenate was used for biochemical investigations. The liver homogenate was assayed for the estimation of carbohydrate metabolic enzymes and lipid profile.

\section{Lipid profile and carbohydrate metabolizing enzymes}

Lipid profile (total cholesterol, high-density lipoprotein (HDL) cholesterol, low -density lipoprotein (LDL) and triglycerides) levels in serum were determined according to the (Assmann et al., 1983). Glucose-6-phosphatase was determined by the method of Koide and Oda (1959). Glucose-6-phosphate dehydrogenase was estimated by the method of Bergmeyer (1984).

\section{Statistical analysis}

Each value represents mean value $\pm S D$ of three experiments carried out each in triplicate. One-way ANOVA and Student's t-test (SPSS program; version 11.5) were carried out to compare the data with the level of significance set at $p<0.05$.

\section{RESULTS AND DISCUSSIONS}

Different phytochemicals have various protective and therapeutic effects which are essential to prevent diseases and maintain a state of well being. The medicinal value of plants lies in some chemical substances known as phytochemicals that have a definite physiological action on the human body. The most important of these bioactive constituents of plants are alkaloids, tannins, saponins, terpenoids, steroids, glycosides, flavanoids and phenolic compounds (Hill, 1952). Phytochemical screening of EtALL and EtASL extracts were performed which revealed the presence of phytoconstituents such as alkaloids, tannins, flavonoids, phenols and terpenoids. Some of the compounds isolated from both the plants are three flavonoids, 5,7,20,30,40-pentamethoxyflavone, 20-hydroxy-2,40,60-tri methoxychalcone and dihydroskullcapflavone I, together with 17,19,20trihydroxy-5 $\alpha, 8 \beta \mathrm{H}, 9 \_\mathrm{H}, 10 \beta$-labd-13-en-16,15-olactone, a known diterpenoid and six known flavonoids,5-hydroxy7,8-dimethoxyflavanone, 5-hydroxy-7,8,20,30,40pentamethoxyflavone, 5,20-dihydroxy-7methoxyflavanone 5,20-dihydroxy-7,8-dimethoxyflavone, 5,20-dihydroxy-7-methoxyflavone and 5,20-dihydroxy-7methoxyflavone 20-O- $\beta$-dglucopyranoside were isolated from the whole plant of Andrographis lineata (Kishore et al., 2003). Two new acylated flavone glucosides, skullcapflavone I 2'-O-b-D-(30-Ecinnamoyl)glucopyranoside and skullcapflavone I 2'-O-bD-(20-E-cinnamoyl) glucopyranoside, together with skullcapflavone I 2'-O-b-D- glucopyranoside and andrographidine $C$ have been isolated from the whole plant of Andrographis serpyllifolia (Damu et al.,1999).

A sudden increase in blood glucose levels, which causes hyperglycemia in T2D diabetes patients, occurs as the result of the hydrolysis of glucose uptake due to intestinal a-glucosidases (Gray, 1995). An effective strategy for the management of T2D patients involving the profound inhibition of intestinal a-glucosidases (Krentz and Bailey, 2005) is warranted. Several natural resources have been evaluated for their ability to suppress the production of glucose from carbohydrates in the gut or glucose absorption from the intestine (Matsui et al., 2007). These findings led us to a further functional investigation of inhibitory effects of EtALL and EtASL extracts against $\alpha$-glucosidase enzyme (Table 1 ) to elucidate the mechanism of antidiabetic activity. EtALL(IC ${ }_{50}$ value $10.12 \mu \mathrm{g} / \mathrm{ml}$ ) and EtASL (IC ${ }_{50}$ value $11.39 \mu \mathrm{g} / \mathrm{ml}$ ) 
Table 1. In vitro a-glucosidase inhibition of EtALL and EtASL.

\begin{tabular}{lccc}
\hline Sample & Concentration $(\mu \mathrm{g} / \mathrm{ml})$ & $\%$ Inhibition & $\mathbf{I C}_{50}(\boldsymbol{\mu g} / \mathrm{ml})$ \\
\hline \multirow{3}{*}{ Acarbose } & 0.1 & $31.53 \pm 0.14$ & \\
& 0.5 & $72.49 \pm 0.09$ & 0.312 \\
& 1.0 & $82.92 \pm 0.12$ & \\
EtALL & 10 & $46.34 \pm 0.2$ & 10.19 \\
& 50 & $68.02 \pm 0.18$ & \\
\multirow{2}{*}{ EtASL } & 100 & $73.14 \pm 10.19$ & \\
& 10 & $43.86 \pm 0.06$ & 11.39 \\
\hline
\end{tabular}

Results are expressed as mean \pm S.E.M; $n=3$.

Table 2. MTT assay for EtALL and EtASL treated 3T3-L1 cell line.

\begin{tabular}{lcc}
\hline \multirow{2}{*}{$\begin{array}{l}\text { Concentration of EtALL and } \\
\text { EtASL }(\boldsymbol{\mu g} / \mathbf{m l})\end{array}$} & \multicolumn{2}{c}{ Percentage of viability $(\%)$} \\
\cline { 2 - 3 } Control cells & 100 & EtASL \\
6.5 & $94.61 \pm 2.71$ & 100 \\
12.5 & $94.1 \pm 1.54$ & $95.43 \pm 2.44$ \\
25 & $89.26 \pm 2.01$ & $90.01 \pm 2.89$ \\
50 & $84.89 \pm 2.33$ & $86.47 \pm 4.56$ \\
100 & $67.25 \pm 1.67$ & $82.44 \pm 3.31$ \\
200 & $59.07 \pm 1.78$ & $74.89 \pm 2.38$ \\
\hline
\end{tabular}

Results are expressed as Mean \pm S.E.M; $n=3$.

exhibited stronger inhibitory activity for a-glucosidase which was comparable with the commercial carbohydrate digestive enzyme inhibitor, Acarbose with the $\mathrm{IC}_{50}$ value $0.312 \mu \mathrm{g} / \mathrm{ml}$. To determine whether the EtALL and EtASL extracts inhibit the cell viability or proliferation of preadipocytes, the cultured preconfluent 3T3-L1 cells were treated with or without various concentrations of EtALL and EtASL extract for $48 \mathrm{~h}$. As illustrated in Table 2 , both the extracts over a dose range of 100 and 200 $\mu \mathrm{g} / \mathrm{ml}$ influenced the metabolism of MTT by 3T3-L1 preadipocytes and concentration ranging 6.5 to $50 \mu \mathrm{g} / \mathrm{ml}$ exhibited no cytotoxicity, which means they do not influence the cell viability of 3T3-L1 preadipocytes.

DM is characterized by increased blood glucose levels and disturbances in the carbohydrate, fat and protein metabolism (Apparao et al., 2003). The insulin stimulated glucose uptake in adipose tissue is critical for reducing post prandial blood glucose concentration. 3T3-L1 cells are an excellent experimental model to quickly screen the effects of crude drugs on glucose uptake. In the current study we have demonstrated for the first time that EtALL and EtASL extract have insulin like effects in 3T3-L1cells which is a classic target tissue of insulin and plays important roles in the maintenance of glucose homeostasis .It was found that both the extracts significantly increased glucose uptake comparable to the effects of standard Insulin (Table 3) which may have the potential for insulin mimetic activity.

Further the antidiabetic effects of both the extracts were evaluated in the in vivo model. In the present investigation, STZ was selected for induction of diabetes in rats which is known for its selective pancreatic $\beta$-cell cytotoxicity and is less toxic than alloxan (Eliza et al., 2009); it also allows a consistent maintenance of diabetes (Raju and Balaraman, 2008).

This model was used to assess the effect of leaves of EtALL and EtASL on hyperglycemia and metabolic disorders related to diabetes. Since no acute toxicity was observed, the EtALL and EtASL extract was prepared and administered to normoglycemic rats at a dosage of 200 and $400 \mathrm{mg} / \mathrm{kg}$ b.w. to determine the dose dependent effect on fasting blood sugar concentration after acute administration. Changes in the blood glucose level of each group of animals were followed during a $2 \mathrm{~h}$ period (Table 4). From the results, it is clear that EtALL and EtASL extract showed no significant effect on normoglycemic rats. It was observed that EtALL and EtASL extract at a dose of $200 \mathrm{mg} / \mathrm{kg}$ b.w. did not show any remarkable hypoglycemic activity in either normoglycemic or STZ- induced diabetic rats. However, the EtALL or EtASL extract, at a dose of $400 \mathrm{mg} / \mathrm{kg}$ b.w., showed significant hypoglycemic activity in diabetic rats, 
Table 3. Glucose uptake rate of EtALL and EtASL extracts in 3T3-L1 cell line.

\begin{tabular}{lcc}
\hline Concentration of EtALL and EtASL & \multicolumn{2}{c}{ Glucose uptake rate (\%) } \\
\cline { 2 - 3 }$(\boldsymbol{\mu} \mathbf{g} / \mathbf{m l})$ & EtALL & EtASL \\
\hline Control cells & 100.00 & 100.00 \\
25 & $103.26 \pm 2.23$ & $105.32 \pm 1.89$ \\
50 & $110.21 \pm 1.78$ & $113.87 \pm 2.51$ \\
75 & $117.54 \pm 2.55$ & $118.35 \pm 2.43$ \\
1.0 Insulin (Standard) & \multicolumn{2}{c}{$195.03 \pm 9.25$} \\
\hline
\end{tabular}

Results are expressed as Mean \pm S.E.M; $n=3$.

Table 4. Fasting blood sugar of normoglycemic rats after acute treatment with EtALL and EtASL extract.

\begin{tabular}{lcccc}
\hline \multirow{2}{*}{ Extract } & \multicolumn{4}{c}{ Blood glucose $\mathbf{~} \mathbf{g} / \mathbf{d L}$} \\
\cline { 2 - 5 } & $\mathbf{0} \mathbf{~} \mathbf{m i n}$ & $\mathbf{3 0} \mathbf{~}$ in & $\mathbf{6 0} \mathbf{~}$ in & $\mathbf{1 2 0} \mathbf{~}$ in \\
\hline Normal & $75.6 \pm 3.4$ & $81.4 \pm 3.2$ & $73.4 \pm 2.4$ & $71.5 \pm 3.1$ \\
Normal+EtALL $(200 \mathrm{mg} / \mathrm{kg}$ b.w.) & $82.4 \pm 3.3$ & $83.1 \pm 1.3$ & $84.6 \pm 3.4$ & $80.4 \pm 1.3$ \\
Normal+EtALL (400 mg/kg b.w.) & $95.5 \pm 3.3$ & $94.5 \pm 1.3$ & $106.5 \pm 3.4$ & $93.2 \pm 1.3^{* *}$ \\
Normal+EtASL (200 mg/kg b.w.) & $81.4 \pm 3.5$ & $83.6 \pm 1.2$ & $85.7 \pm 3.7$ & $80.5 \pm 1.8$ \\
Normal+EtASL (400 mg/kg b.w.) & $88.4 \pm 1.3$ & $90.1 \pm 0.8$ & $104.6 \pm 2.3$ & $97.4 \pm 2.0^{* *}$ \\
\hline
\end{tabular}

Values are expressed in Mean \pm S.E.M of six animals. ${ }^{*}: P<0.05 ;{ }^{* *}: P<0.01$.

Table 5. Effect of the EtALL and EtASL extracts on oral glucose tolerance test.

\begin{tabular}{lcccc}
\hline \multirow{2}{*}{ Group } & \multicolumn{4}{c}{ Blood glucose level $\mathbf{~} \mathbf{m g} / \mathbf{d L})$} \\
\cline { 2 - 5 } & $\mathbf{0 ~} \mathbf{~ m i n}$ & $\mathbf{3 0} \mathbf{~}$ in & $\mathbf{6 0} \mathbf{~} \mathbf{i n}$ & $\mathbf{1 2 0} \mathbf{~ m i n}$ \\
\hline Normal control & $81.02 \pm 2.41$ & $97.7 .29 \pm 1.15$ & $145.05 \pm 1.35$ & $107.68 \pm 1.70$ \\
EtALL $(200 \mathrm{mg} / \mathrm{kg} \mathrm{bw})$ & $82.0 \pm 2.9$ & $87.2 \pm 1.7$ & $132.1 \pm 3.2$ & $84.0 \pm 4.9$ \\
EtALL $(400 \mathrm{mg} / \mathrm{kg} \mathrm{bw})$ & $84.0 \pm 4.9$ & $93.7 \pm 0$. & $144.5 \pm 2.5$ & $87.3 \pm 4.4$ \\
EtASL $(200 \mathrm{mg} / \mathrm{kg} \mathrm{bw})$ & $82.5 \pm 3.2$ & $86.4 \pm 2.3$ & $135.2 \pm 4.3$ & $83.9 \pm 3.9$ \\
EtASL $(400 \mathrm{mg} / \mathrm{kg} \mathrm{bw})$ & $85.7 \pm 2.7$ & $95.5 \pm 3.6$ & $142.6 \pm 3.6$ & $89.5 \pm 4.5$ \\
Diabetic control & $380.5 \pm 5.3$ & $384.8 \pm 9.2$ & $385.7 \pm 7.5$ & $399.2 \pm 6.9$ \\
Diabetic+EtALL $(200 \mathrm{mg} / \mathrm{kg} \mathrm{bw})$ & $384.2 \pm 9.0$ & $389.6 \pm 10.2$ & $394.8 \pm 11.4$ & $414.6 \pm 9.0$ \\
Diabetic+EtALL $(400 \mathrm{mg} / \mathrm{kg} \mathrm{bw})$ & $437.93 \pm 1.20$ & $489.61 \pm 1.34^{*}$ & $406.38 \pm 1.15^{* *}$ & $288.15 \pm 1.12^{* *}$ \\
Diabetic+ EtASL $(200 \mathrm{mg} / \mathrm{kg} \mathrm{bw})$ & $382.2 \pm 2.3$ & $387.3 \pm 7.3$ & $391.2 \pm 12.6$ & $408.1 \pm 6.7$ \\
Diabetic+ EtASL $(400 \mathrm{mg} / \mathrm{kg} \mathrm{bw})$ & $445.44 \pm 0.92$ & $496.34 \pm 1.39^{* *}$ & $420.28 \pm 1.12^{* *}$ & $296.34 \pm 1.03^{* *}$ \\
\hline
\end{tabular}

Values are expressed in Mean \pm S.E.M of six animals. ${ }^{*}, \mathrm{P}<0.05 ;{ }^{* *}, \mathrm{P}<0.01 \mathrm{c}$ compared with diabetic control group.

but not in normoglycemic rats (Table.5). The improvement in glucose tolerance of diabetic rats treated with $400 \mathrm{mg} / \mathrm{kg} \mathrm{b.w}$. of EtALL and EtASL extract was brought by lowering the initial blood glucose level from $437.93 \pm 1.20$ to $288.15 \pm 1.12 \mathrm{mg} / \mathrm{dL}$ (EtALL) and $445.44 \pm 0.92$ to $296.34 \pm 1.03 \mathrm{mg} / \mathrm{dL}$ (EtASL) at $120 \mathrm{~min}$. In the untreated diabetic group, the fasting blood glucose increased from the initial value of $380.5 \pm 5.3$ to $399.2 \pm$ $6.9 \mathrm{mg} / \mathrm{dL}$. Many researchers reported similar pattern of reduction in the blood glucose level in the OGTT analysis in Andrographis paniculata (Rammohan et al 2008), Coccinia cordifolia and Catharanthus roseus (Islam et al., 2009), Telfaria occidentalis (Olorunfemi et al., 2010) and
Calotropis gigantean (Nanu et al., 2011). Since no hypoglycemic effect was observed at $200 \mathrm{mg} / \mathrm{kg} \mathrm{b.w.} \mathrm{for}$ both the extracts in any of the rat models, it was decided to determine the chronic effect of both the extracts at a dosage of $400 \mathrm{mg} / \mathrm{kg}$ b.w. for 28 days. Over-production (excessive hepatic glycogenolysis and gluconeogenesis) and decreased utilization of glucose by the tissues are the fundamental basis of hyperglycemia in DM (Kumar et al., 2010). There may be several causes for persistant hyperglycemia and the most important among them is the failure of blood sugar regulation (Bolkent et al., 2000). High plasma levels of insulin and glucose due to insulin resistance are a major component of the metabolic 
Table 6. Effect of the EtALL and EtASL extracts extract on fasting blood glucose level and plasma insulin level.

\begin{tabular}{|c|c|c|c|c|}
\hline \multirow{2}{*}{ Group } & \multicolumn{3}{|c|}{ Fasting blood glucose level (mg/dL) } & \multirow{2}{*}{$\begin{array}{l}\text { Plasma insulin } \\
(\mathrm{U} / \mathrm{ml})\end{array}$} \\
\hline & Oth day & 15thday & 28th day & \\
\hline Normal control & $77.5 \pm 4.39$ & $86.1 \pm 3.82$ & $91.5 \pm 1.27$ & $89.5 \pm 4.21$ \\
\hline Diabetic control & $259.3 \pm 7.41$ & $355.5 \pm 1.81$ & $400.7 \pm 1.21$ & $390.2 \pm 1.56$ \\
\hline EtALL (400 mg/kg bw) & $290.6 \pm 3.62$ & $354.5 \pm 1.30^{\star \star}$ & $283.6 \pm 2.11^{\star *}$ & $156.8 \pm 1.22^{* *}$ \\
\hline EtASL (400 mg/kg bw) & $291.2 \pm 3.22$ & $352.6 \pm 1.23^{* *}$ & $285.7 \pm 2.13^{* *}$ & $154.5 \pm 1.26^{* *}$ \\
\hline Glibenclamide $(600 \mu \mathrm{g} / \mathrm{kg} \mathrm{bw})$ & $294.5 \pm 3.51$ & $378.3 \pm 1.67^{\star *}$ & $308.2 \pm 2.42^{\star \star}$ & $212.4 \pm 2.11^{\star \star}$ \\
\hline
\end{tabular}

Values are expressed in Mean \pm S.E.M of six animals. ${ }^{*}, \mathrm{P}<0.05 ;{ }^{* *}, \mathrm{P}<0.01$ compared with diabetic control group.

Table 7. Effect of the EtALL and EtASL extract on liver and mucle glycogen content in STZ induced diabetic rats after 28 days treatment (Mean \pm SEM) (mg/100 mg wet weight).

\begin{tabular}{lcc}
\hline \multirow{2}{*}{ Groups } & \multicolumn{2}{c}{ Glycogen content } \\
\cline { 2 - 3 } & Liver & Muscle \\
\hline Normal control & $9.8 \pm 1.2$ & $46.3 \pm 2.2$ \\
Diabetic control & $6.5 \pm 3.4$ & $12.5 \pm 2.4$ \\
EtALL $(400 \mathrm{mg} / \mathrm{kg} \mathrm{bw})$ & $10.6 \pm 3.6^{* *}$ & $44.3 \pm 2.8^{* *}$ \\
EtASL $(400 \mathrm{mg} / \mathrm{kg} \mathrm{bw})$ & $11.4 \pm 3.1^{* *}$ & $43.2 \pm 2.3^{* *}$ \\
Glibenclamide $(600 \mu \mathrm{g} / \mathrm{kg} \mathrm{bw})$ & $11.2 \pm 2.9^{* *}$ & $42.8 \pm 2.9^{* *}$ \\
\hline
\end{tabular}

Values are expressed in Mean \pm S.E.M of six animals. ${ }^{*}, \mathrm{P}<0.05 ;{ }^{* *}$ : $\mathrm{P}<0.01$ compared with diabetic control group.

syndrome. If insulin resistance exists, more insulin needs to be secreted by the pancreas. If this compensatory increase does not occur, blood glucose concentrations increases leading to diabetes (Graham et al., 2001). Fivefold increase in blood glucose level and more than two fold decrease in secretion of plasma insulin was observed at the end of $28^{\text {th }}$ day in EtALL and EtASL extract $(400 \mathrm{mg} / \mathrm{kg}$ b.w.) treated diabetic rats (Table 6). The glibenclamide treated diabetic rats also showed better glucose lowering ability and an increase in plasma insulin level compared to the diabetic control rats. This hypoglycemic effect of both the extracts may be due to the presence of bioactive compounds belonging to flavanoids or terpenoid group of compounds which triggers the pancreatic secretion of insulin from the existing $\beta$-cells (Kishore et al.,2003; Damu et al.,1999; Li et al., 2004). The glucose lowering ability and insulin secretary activity was well correlated by Eliza et al. (2009) in Costus specious, Kondeti et al. (2010) in Petrocarpus santalinus and Arokiyaraj et al. (2011) in Hypericum perforatum.

Glycogen is the primary intracellular storable form of glucose and its level in various tissues is a direct reflection of insulin activity as insulin promotes intracellular glycogen deposition by stimulating glycogen synthase and inhibiting glycogen phosphorylase (Golden et al., 1979). The glycogen content of skeletal muscle and liver markedly decreased in diabetic rats (Welihinda and Karuanayake, 1986) in proportion to insulin deficiency (Stalmans et al., 1997). In our study, decreased levels of muscle and hepatic glycogen were observed in diabetic control rats. This may be due to the stimulation of insulin release from $\beta$-cells (Lolitkar et al., 1996). When EtALL and EtASL extract was administered at $400 \mathrm{mg} / \mathrm{kg}$ b.w., increased muscle and liver glycogen content was increased when compared to the diabetic control rats (Table 7). Glibenclamide treated rats also showed a significant rise in the muscle and liver glycogen content compared to the diabetic control rats. Similar results were reported in the extracts of Eugenia jambolana (Sharma et al., 2003) and C. specious (Eliza et al., 2009) which showed increased level of muscle and liver glycogen content in diabetic rats.

The most common lipid abnormalities in diabetes are hypertriglyceridaemia and hypercholesterolaemia (Khan et al., 1995; Mitra et al., 1995). The development of hypertriglyceridemia in uncontrolled diabetes is a consequence of a number of metabolic abnormalities that occur sequentially. There was a significant decrease in HDL-c cholesterol and increase in total cholesterol, triglycerides and LDL-c level in diabetic control rats when compared to the normal rats (Lopez, 2001). EtALL and EtASL $(400 \mathrm{mg} / \mathrm{kg}$ b.w.) extract treated diabetic rats significantly reduced total cholesterol, triglycerides and increased HDL cholesterol compared with diabetic control (Table 8). The glibenclamide treated diabetic rats showed an increase in HDL-c level, triglycerides and LDL-c level when compared to diabetic rats. These findings are in agreement with Ravi et al. (2005) in E. jambolina and Daisy et al. (2009) reported in Elephantopus scaber. 
Table 8. Effect of EtALL extract on serum lipid profile in normal and streptozotocin induced diabetic rats.

\begin{tabular}{lcccc}
\hline \multirow{2}{*}{ Group } & \multicolumn{4}{c}{ Serum lipid profile } \\
\cline { 2 - 5 } & Total cholesterol (mg/dl) & HDL-c (mg/dl) & LDL-c (mg/dl) & Triglycerides mg/dl) \\
\hline Normal & $95.85 \pm 3.7$ & $56.43 \pm 4.8$ & $80.42 \pm 0.9$ & $16.16 \pm 1.4$ \\
Diabetic control (STZ-40 mg / kg b.w). & $247.12 \pm 4.5$ & $26.61 \pm 1.5$ & $146.44 \pm 1.2$ & $40.23 \pm 2.8$ \\
Diabetes+ EtALL (400 mg/ kg b.w.) & $109.42 \pm 10.3^{* *}$ & $50.22 \pm 3.2^{* *}$ & $80.67 \pm 5.1^{* *}$ & $13.52 \pm 0.7^{* *}$ \\
Diabetes+ EtASL (400 mg/ kg b.w.) & $187.34 \pm 3.6^{*}$ & $35.81 \pm 1.3^{*}$ & $91.81 \pm 5.3^{*}$ & $30.64 \pm 2.5^{*}$ \\
Diabetes + Glibenclamide (600 pg/ kg b.w.) & $124.34 \pm 5.1^{* *}$ & $44.87 \pm 3.8^{* *}$ & $90.68 \pm 1.1^{* *}$ & $6.37 \pm 0.8^{* *}$ \\
\hline
\end{tabular}

Values are expressed in Mean \pm S.E.M of six animals. ${ }^{*}: p<0.05 ;{ }^{* *}: p<0.01$ compared with diabetic control group.

Table 9. Effect of EtALL extract on carbohydrate metabolizing enzyme in liver of normal and streptozotocin induced diabetic rats.

\begin{tabular}{lccc}
\hline Group & $\begin{array}{c}\text { Hexokinase } \\
\text { (U/g protein) }\end{array}$ & $\begin{array}{c}\text { Glucose-6-phosphatase } \\
\text { (U/g protein) }\end{array}$ & $\begin{array}{c}\text { Fructose -1, 6- bisphosphatase } \\
\text { (U/g protein) }\end{array}$ \\
\hline Normal & $142.81 \pm 4.8$ & $0.162 \pm 0.01$ & $0.331 \pm 0.01$ \\
Diabetic control (STZ-40 mg / kg b.w.) & $109.33 \pm 4.7$ & $0.272 \pm 0.02$ & $0.517 \pm 0.03$ \\
Diabetes+ EtASL (400 mg/kg b.w.) & $139.12 \pm 8.1^{* *}$ & $0.171 \pm 0.02^{* *}$ & $0.413 \pm 0.04^{* *}$ \\
Diabetes+ EtASL (400 mg/kg b.w.) & $127.21 \pm 4.3^{*}$ & $0.210 \pm 0.06^{*}$ & $0.495 \pm 0.04^{*}$ \\
Diabetes + Glibenclamide (600 $\mathrm{\mu g} / \mathrm{kg}$ b.w.) & $137.14 \pm 9.4^{* *}$ & $0.182 \pm 0.02^{* *}$ & $0.435 \pm 0.04^{* *}$ \\
\hline
\end{tabular}

Values are expressed in Mean \pm S.E.M of six animals. ${ }^{*}, p<0.05 ;{ }^{*},: p<0.01$ compared with diabetic control group.

Thus, it is reasonable to conclude that EtALL and EtASL extract could modulate blood lipid abnormalities. Hexokinase, glucose-6-phosphatase and fructose -1, 6bisphosphatase are rate limiting glycolytic enzymes that are severely impaired during diabetes condition. These enzymes play a very important role in the final step of glucogenolysis and gluconeogenesis (Hassan et al., 2009). A decrease in the activity of hexokinase, glucose6-phosphatase and fructose -1,6- bisphosphatase has been shown to slow down the pentose phosphate pathway under diabetic conditions (Abdel-Rahim et al., 1992).

There was a significant decrease by 2 fold in hexokinase activity and an increase in glucose-6phosphatase and fructose -1,6-bisphosphatase activity in the diabetic control rats compared to the normal rats. This might be due to the activation or increased synthesis of the enzymes contributing to increased hepatic glucose production during diabetes activation of the gluconeogenic enzymes or may also be due to state of insulin deficiency given that under normal conditions, insulin functions as a suppressor of gluconeogenic enzymes (Pushparaj et al., 2001).

Treatment with EtALL and EtASL extract at $400 \mathrm{mg} / \mathrm{kg}$ b.w. reversed the above changes significantly. The reduction in the activities of gluconeogenic enzymes can result in the decreased concentration of glucose in blood. Similar pattern of activity was observed with the glibenclamide treated rats whereas the diabetic control rats showed significant decrease in hexokinase activity and an increase in glucose-6-phosphatase and fructose -
1, 6-bisphosphatase activity in the diabetic control rats (Table 9).The glibenclamide treated rats showed comparable more effect than the extract treated rats. The increased activities of gluconeogenic enzymes were shown to be reduced after treatment with other medicinal plants (Pushparaj et al., 2007; Pari and Amarnath Satheesh, 2004; Maiti et al., 2004), in experimental diabetic animals and our results are comparable with these reports.

\section{Conclusion}

In this study, several models of in vitro and in vivo assays were applied to evaluate the antidiabetic effect of EtALL and EASL extracts. As a conclusion it could be speculated that the observed antidiabetic activity of EtALL and EtASL extract might be related to the presence of phytoconstituents such as flavonoids and terpenoids content, having the potential to impart beneficial therapeutic effect in diabetes. Glucose and fat are two major substrates for energy production in animals. Coordination between their metabolisms in providing energy is sophisticated and is regulated by many hormonal and metabolic factors. Disturbance of the energy homeostasis may cause serious clinical syndromes that are manifested by abnormal blood glucose or fatty acid levels. Although adipose tissue accounts for only $5-20 \%$ of glucose disposal, much of the work on insulin stimulated glucose transport has been performed in adipocytes, due to the fact that many mechanistic studies with regard to 
insulin's action have been easier to carry out in this tissue. This study also establishes a correlation between adipogenesis and carbohydrate metabolism which may be of considerable interest in preventing the ill effects of obesity related diabetes. However the EtALL and EtASL extracts should be investigated to find out the active principles for antidiabetic actions. Further studies are in progress to identify the lead molecule.

\section{ACKNOWLEDGEMENTS}

The authors thank the UGC and DST (Govt.of India) for providing financial assistance to carry this research work.

\section{ABBREVIATIONS}

TZDs, Thiazolidinediones; AL, Andrographis lineata Wall.ex.Nees; AS, Andrographis serpyllifolia Wt.lc; EtALL, ethanolic leaf extracts of ndrographis lineata Wall.ex.Nees; EtASL, ethanolic leaf extracts of ndrographis serpyllifolia Wt.Ic; DMEM, Dulbecco's modified Eagle's medium; FBS, fetal bovine serum; OGTT, oral glucose tolerance test; STZ, streptozotocin; HDL, high-density lipoprotein; LDL, low -density lipoprotein.

\section{REFERENCES}

Abdel-Rahim EA, El-Saadany SS, Abo-Eytta AM, Wasif M (1992). The effect of Sammo administration on some fundamental enzymes of pentose phosphate pathway and energy metabolites of alloxanized rats. Nah. 36: 8-14.

Ahmad G, Hosseim Fallah, Fariba S, Mansour (2008). The inhibitory effect of some Iranian plants extracts on the alpha glucosidase. Iranian. J. Basic. Med. Sci. 11: 1-9.

Alagesaboopathi C, Balu S (1995). Antivenom activities of some Andrographis species. Ancient Sci.Life.14: 187-190.

Apparao C, Kameswararao B, Kesavulu MM (2003). Evaluation of antidiabetic effect of Momordica cymbalaria fruit in alloxan -diabetic rats. Fito. 74:7-13.

Arokiyaraj S, Balamurugan R, Augustian, P (2011). Antihyperglycemic effect of Hypericum perforatum ethyl acetate extract on streptozotocin-induced diabetic rats. A. Pac. J. Trop. Biomed. 11: 386-390.

Assmann G, Schriewer H, Schmitz G, Hagele EO (1983). Quantification of high density lipoprotein cholesterol by precipitation with phospho tungstic acid/MgCl 2 . Clin. Chem. 29: 2026-2030.

Bergmeyer HU (1984). Glucose-6-phosphate dehydrogenase. In: Bergmeyer HU (ed.) Methods of enzymatic analysis. 2nd ed.Weinheim: Verlag Chemie; pp. 222-223.

Bharath C, Manga K (2010). Hypolipidemic activity of Andrographis serpyllifolia. J. Pharm. Res. 3: 769-770.

Bolkent S, Yamardag R, Tabakogluoguz A, Sacaon OO (2000). Effects of chord (Beta vulgaris L.Var.cicla) extract on pancreatic cells in streptozotocin-diabetic rats: a morphologic and biochemical study. J. Ethnopharmacol. 73: 251-259.

Bonner-Weir S (1988). Morphological evidence for pancreatic polarity of beta cell within islets of langerhans. Diabetes. 37: 616-621.

Carrol NV, Longley, RW, Roe, JH (1956). The determination of glycogen in liver and muscle by use of anthrone reagent. J. Biol. Chem. 220:583-593.

Chiasson JL, Josse RG, Hunt JA (1994). Efficacy of acarbose in the treatment of paitents with non insulin dependent diabetes milletus. A multi control clinical trail. Ann. Int. Med. 121: 928-935.

Cho HJ, Park J, Lee HW, Lee YS, Kim JB (2004). Regulation of adipocyte differentiation and insulin action with rapamycin.Biochem. Biophy. Res. Commun. 321:942-948.

Daisy P, Lily V, Cecilia, EP (2009). Comparative studies on the different leaf extracts of Elephantopus Scaber. L on STZ-induced diabetic rats. Euro. J. Sci. Res. 32:304-313.

Damu G, Jayaprakasam B, Gunasekar D, Blond A, Bodo, B (1999). Two acylated flavones glucosides from Andrographis serpyllifolia. Phytochem. 52: 142-151.

Davis S (2006). Insulin oral hypoglycemic agents and the pharmacology of the endocrine pancrease. 11th ed. New York: pp.1613-1646.

Eliza J, Daisy P, Ignacimuthu S, Duraipandiyan V (2009). Antidiabetic and antilipidemic effect of eremanthin from Costus speciosus (Koen.) Sm., in STZ-induced diabetic rats. Chem. Biol. Interact. 182: 67-72.

Gamble JS (1956). Flora of the presidency of Madras. Botanical Survey of India, Vol.2, Calcutta. pp-345-347.

Ghosh MN (1984). Fundamentals of experimental pharmacology. Calcutta: Scientific Book Agency; pp.153.

Golden S, Wals PA, Okajima F, Katz J (1979). Glycogen synthesis by hepatocytes from diabetic rats, Biochem. J. 182: 727-734.

Govindachari TR, Parathasarathy PC, Pai BR, Kalyanaraman PS (1968). Chemical investigation of Andrographis serpyllifolia :isolation and structure of serpyllin, a new flavones. Tetra. 24:7027-7032.

Graham TE, Sathasivam P, Rowland M, Marko N, Greer F, Battram D (2001). Caffeine ingestion elevates plasma insulin response in humans during an oral glucose tolerance test. Can. J. Physio. and Pharmacol. 79:559-565.

Gray DM (1995). Carbohydrate digestion and absorption role of small intestine. N.Engl. J. Med. 29: 1225-1230.

Hassan HA, El-Agmy SM, Gaur RL, Fernando A, Raj MHG, Ouhtit A (2009). In vivo evidence of hepato and reno-protective effects of garlic oil against sodium nitrite-induced oxidative stress. Int. J. Biol. Sci. 5: 249-255.

Hill AF (1952). Economic botany. A text book of useful plants and plant products. 2nd edn. Mcgraw-Hill bookcompany Inc, New York.

Ignacimuth S, Ayyanar M, Sharasivaraman K (2006). Ethanobotanical investigations among the tribes in Madurai district of Tamilnadu (India). J. Ethano. Ethanomed. 2: 1-20.

Islam MA, Akhtar MA, Khan MR, Hossain MS, Alam AH, Ibne-Wahed MI, Amran, MS, Rahman BM, Ahmed M (2009). Oral glucose tolerance test (OGTT) in normal control and glucose induced hyperglycemic rats with Coccinia cordifolia and Catharanthus roseus L. Pak .J. Pharm. Sci. 22: 402-404.

Ji-Youn Y, Hyo-Young P, Kyung-Hea C (2004). Anti-hyperglycemic activity of Commelina communis L.: inhibition of a-glucosidase. Diabetes Res. Clin. Practice. 66: S149-S155.

Karalee JJ, Anderson RA, Graves DA (2001). Hydroxychalcone derived from cinnamon functions as a mimetic for insulin in 3T3-L1 adipocytes. J. Am. Coll. Nutr. 20: 327-336.

Khan BA, Abraham A, Leelamma S (1995). Hypoglycemic action of Murraya koenigii (curry leaf), Brassica juncea (mustard); mechanism of action. Ind. J. Biochem. Biophys. 32: 106-108.

Kishore PH, Reddy MV, Reddy MK, Gunasekar D (2003). Flavanoids from Andrographis lineata. Phytochem. 63: 457-461.

Koide $H$, Oda $T$ (1959). Pathological occurrence of glucose-6phosphatase in serum in liver diseases. Clin. Chim. Acta. 4: 554-561.

Kondeti VK, Badri KR, Maddirala DR, Thur SKM, Fatima SS, Kasetti RB (2010). Effect of Pterocarpus santalinus bark, on blood glucose, serum lipids, plasma insulin and hepatic carbohydrate metabolic enzymes in streptozotocin insulin and hepatic carbohydrate metabolic enzymes in streptozotocin induced diabetic rats. Food Chem. Toxicol. 48: $1281-1285$

Krentz AJ, Bailey CJ (2005). Oral antidiabetic agents and its current role in type 2 diabetes mellitus. Drugs. 65: 385-411.

Kumar S, Kumar V, Prakash O (2010). Antidiabetic and anti-lipemic effects of Cassia siamea leaves extract in streptozotocin induced diabetic rats. Asia. Pac. J. Trop. Med. 3: 871-873.

Lelliott C, Vidal-Puig AJ (2004). Lipotoxicity, an imbalance between lipogenesis de novo and fatty acid oxidation. Int. J. Obes. Metab. Dis. 28: 22-28. 
Li WL, Zheng HC, Bukuru J, De KN (2004). Natural medicines used in the traditional Chinese medical system for therapy of diabetes mellitus. J. Ethnopharmacol. 92:18-21.

Liu F, Kim J, Li Y, Liu X, Li J, Chen X (2001). An extract of Lagerstroemia speciosa $L$. has insulin-like glucose uptakestimulatory and adipocyte differentiation-inhibitory activities in 3T3-L1 cells. J. Nutr. 131: 2242-2247.

Lolitkar MM, Rao MRR, Lolitkar MM, Rajarama RMR (1996). Pharmacology of a hypoglycaemic principle isolated from the fruits of Momordica charantia Linn. Ind. J. Pharm. 28: 129-133.

Lopez A (2001). Respiratory system, thoracic cavity, and pleura. In: Thomson's Special Veterinary Pathology", 3rd Ed., McGavin, MD, Carlton WW and Zachari JF, Eds, Mosby, Philadelphia, 125-195.

Maiti R, Jana D, Das UK, Ghosh D (2004). Antidiabetic effect of aqueous extract of seed of Tamarindus indica in streptozotocininduced diabetic rats. J. Ethnopharmacol. 92: 85-91.

Matsui T, Tanaka T, Tamura S, Toshima A, Miyata Y, Tanaka K, Matsumoto $K$ (2007). $\alpha$-glucosidase inhibitory profile of catechins and the aflavins. J. Agric. Food Chem. 55: 99-105.

Mitra SK, Gopumadhavan S, Muralidhar TS, Anturlikar SD Sujatha MB (1995). Effect of D-400, a herbo mineral preparation on lipid profile, glycated hemoglobinand glucose tolerance in streptozotocin induced diabetes in rats. Ind. J. Exp. Biol. 33:798-800.

Nanu RR, Havagiray RC, Raghuveer I, Ramesh C (2011). Hypoglycemic effect of Calotropis gigantea Linn. leaves and flowers in streptozotocin-induced diabetic rats. Oma. Medi. J. 26:104-108.

Olorunfemi E, Patrick B, Eyong E, Oladoja A, Akeem A (2010). Effect of Telfairia occidentalis on oral glucose tolerance in rat. Afr, J. Pharm. Pharmacol. 4:368-372.

Pari L, Amarnath SM (2004). Antidiabetic activity of Boerhaavia diffusa L.: effect on hepatic key enzymes in experimental diabetes. J. Ethnopharmacol. 91: 109-113.

Patil RN, Patil RY, Ahirwar B, Ahirwar D (2011). Evaluation of antidiabetic and related actions of some Indian medicinal plants in diabetic rats. Asia. Pac. J. Trop. Med. 4: 20-23.

Pushparaj PN, Low HK, Manikandan J, Tan BKH, Tan CH (2007). Antidiabetic effects of Cichorium intybus in streptozotocin-induced diabetic rats. J. Ethnopharmacol. 111: 430-434.

Rajaram K, Suresh KP (2011). In-vitro antioxidant and antidiabetic activity of Tephrosia tinctoria Pers. An endemic medicinal plant of South India. J. Pharm. Res. 3: 891-893.

Raju K, Balaraman R (2008). Antidiabetic mechanisms of saponins of Momordica cymbalaria. Pharmacogn. Mag. 4: 197-206.

Rammohan S, Zaini AM, Amirin S (2008). In vitro a-glucosidase and $\alpha$ amylase enzyme inhibitory effects of Andrographis paniculata extract and andrographolide. A. Biochem. Pol. 55: 391-398.

Ravi K, Rajasekaran S, Subramanian S (2005). Antihyperlipidemic effect of Eugenia jambolina seed kernel on streptozotocin induced diabetes in rats. J. Food Chem. Toxicol. 99:1433-1439.
Sangameswaran B, Chandraganth RT, Jayakar B (2007). Hepatoprotective effects of ethanolic leaf extracts of Andrographis lineata on liver damage caused by carbon tetrachloride rats. Phyto. Res. 22: 124-126.

Sathish UV, Smitha J, Shylaja MD (2009). Antiproliferative, Antioxidant and cyto/DNA protective properties in Andrographis serpyllifolia: Role of Andrographolide and Phenolic acids. Comp. Integ. Med. 6: 1-18.

Satish K, Vivek K, Chandrashekhar MS (2011) In vitro antioxidant and alpha-amylase inhibitory activity of isolated fractions from methanolic extract of Asystasia dalzelliana leaves. Int. J. Pharm. Tech. Res. 3(2): 889-894.

Sharma SB, Nasir A, Prabhu KM, Murthy PS, Dev G (2003). Hypoglycemic and hypolipidemic effect of ethanolic extract of seeds of Eugenia jambolana in alloxan-induced diabetic rabbits. J. Ethnopharmacol. 85: 201-206.

Srinivasan K, Ramarao P (2007). Animal models in type 2 diabetes research: An overview. Indian J. Med. Res. 125: 451-472.

Stalmans W, Cadefau J, Wera S, Bollen M (1997). New insight into the regulation of liver glycogen metabolism by glucose. Biochem. Soc. Trans. 25: 19-25.

Sunil C, Latha G, Palanisamy M, Kalaichelvan K, Paul A (2009). aGlucosidase inhibitory and antidiabetic activities of ethanolic extract of Pisonia alba Span leaves. Int. J. Int. Bio. 6: 41-45.

Tadera K, Minami Y, Takamatsu K, and Matsuoka T (2006). Inhibition of $\alpha$-glucosidase and $\alpha$-amylase by flavonoids. J. Nutr. Sci. Vitaminol. 52:149-153.

Trease GE, Evans WC (1989). Pharmacognosy. 13th ed. London: Bailliere Tindall pp. 683-684.

Triender $P$ (1969). Determination of glucose in blood using glucose oxidase with an alternative oxygen acceptor. Ann. Clin. Biochem. 6: 24-27.

Turner MA (1965) Screening methods in pharmacology. New York: Academic Press;pp. 26.

Va1iathan MS (1998). Healing plants. Curr. Sci.75:1122-1126.

Welihinda J, Karuanayake EH (1986). Extra pancreatic effect of Momordica charantia in rats. J. Ethnopharmacol, 17: 247-255.

Yu-Chiao Y, Hseng-Kuang H, Jia-Huae H, Show-Jen H (2003). Enhancement of Glucose uptake in 3T3-L1adipocytes by Toona sinensis leaf extract. Kao. J. Med. Sci. 19:327-332.

Zimmet PKG, Alberti KG, Shaw J (2001). Global and societal implications of the diabetes Epidemic. Nat. 41:782-787. 